\title{
An Exploratory Look at the Relationship Between Materialistic Values and Goals and Type A Behaviour
}

\author{
Shaun A. Saunders \\ University of the Sunshine Coast, Australia \\ Michael W. Allen \\ University of Sydney, Australia \\ Kay Pozzebon \\ University of the Sunshine Coast, Australia
}

\begin{abstract}
Previous research in Australia has inferred that materialism and its possession-defined 'Success' subtheme described by Richins and Dawson (1992) has characteristics in common with specific Type A behaviour including competitiveness and aggression. Given that Australian materialists appear to have similar inclinations to their North American counterparts, assumptions by the latter that materialism and Type A behaviour fall under the same cultural value of work and wealth might also be applicable in Australia. Hence, the present study aims to explore the relationship between materialism and Type A behaviour, with psychometric measures of each administered to 193 Australian participants. Scores on Materialism were positively correlated with Type A behaviours, while the Success subscale was only significantly correlated with the second Type A item, assessing competitiveness. However, while materialistic pursuits might provide a culturally sanctioned outlet for competitive behaviours deriving from existing Type A personalities, it could also be argued that contemporary consumer society encourages such behaviours.
\end{abstract}

Keywords: materialism, Type A behaviour

In an ongoing effort to develop a psychological profile of materialistic values and attitudes in Australia, the present study aims to explore the relationship between materialism and Type A behaviour.

Social scientists conceptualise materialism in subtly different ways: the combination of envy, nongenerosity, and preservation personality traits (Belk, 1988), defining oneself through material objects (Claxton \& Murray, 1994), a style of consuming (Holt, 1995), those motivated by a need for security (Inglehart, 1977, 1997), and an excessive concern for material possessions (Richins \& Dawson, 1992).

Previous research on macro-level consumer behaviour in Australia suggests that materialistic desires and ambitions (as defined by Richins \& Dawson, 1992) might be associated with reduced life satisfaction (Saunders \& Allen, 2001), and increased levels of depres- sion and anger (Saunders \& Munro, 2000). A possible explanation for this is that in a volatile and constantly fluctuating market-driven society, where individual worth may be valued according to the acquisition of possessions, someone else will always have more possessions, and the possessions that one does own are unlikely to hold value for long. This in turn might lead to frustration, which is a precursor to anger expression (Dollard, Doob, Miller, Mowrer, \& Sears, 1939).

Furthermore, Australian materialists' relative disinterest in the Rokeach value 'Equality' supports the argument that comparisons in the consumer domain are made with the aim of determining relative success or failure, rather than determinations of equality, while the importance of 'Social Recognition' to these persons supports the notion that materialism is based largely on the process of social comparison (Saunders \& Munro, 2001). 
Such a notion is supported by research on materialists outside of Australia, who show a preference for publicly consumed products (Richins, 1994).

Scores on materialism in an Australian sampling frame have also been found to be significantly correlated with individualism generally, and more so with vertical individualism (Saunders, 2007). As vertical individualism not only places the goals of self above those of the community, but also emphasises 'being the best' and is competitive (Singelis, Triandis, Bhawuk, and Gelfand, 1995), it appears to be entirely consistent with contemporary marketing practices.

Materialists in Australia are more interested in 'Pleasure' and a 'Comfortable Life' than a 'World of Peace' or 'Beauty', and are significantly less interested in the Australian environment (Saunders, in press), Biophilia (i.e., a love of life: Saunders, 2001), and, perhaps not surprisingly, notions of Voluntary Simplicity (Saunders, in press).

These materialists are also more likely to watch commercial television, and more conformist than nonmaterialists (Saunders \& Munro, 2000). This finding has also been supported by studies of materialists outside Australia, which have found that materialists are concerned about how others evaluate them and hence strive to make the right impression. These materialists have a greater tendency to self-monitor (Chatterjee \& Hunt, 1996), and conform to normative social influences (Chang \& Arkin, 2002; Schroeder \& Dugal, 1995). In addition, it has been suggested that the acquisition of material goods may be seen as a neurotic defence for unsatisfied Maslowian esteem level needs (Saunders, Munro, \& Bore, 1998).

Further, Australians who score high on materialism — as measured by Inglehart's (1977) scale — also have a high need for security, which manifests in heightened concerns about national security and financial security, and hoarding basic necessities such as food (Allen \& Wilson, 2005). Americans who scored high on materialism were more worried than the less materialistic about personal safety and security and dreamed of death more (Kasser \& Grow Kasser, 2001). Such worries exhibited by materialists, as well as the personality characteristics of materialists previously outlined - particularly those involving competitiveness - seem comparable to a number of traits characteristic of Type A behaviour.

Type A behaviour refers to a cluster of behavioural traits displayed by those individuals who tend to be competitive and achievement orientated, hostile and aggressive, and who feel that they are under time pressure (Day \& Jreige, 2002). On the other hand, at the opposite end of the Type A spectrum, individuals exhibiting 'Type B' behaviour are considered to be relatively relaxed, less hurried, and less competitive (Vecchio, Hearn, \& Southey, 1996). However, both are denoted as a behaviour pattern and have been clarified as a behavioural style (Thoresen \& Powell, 1992) and behavioural disposition (Day \& Jreige, 2002). According to Thoresen and Powell (1992, p. 596), Type A behaviour has generally been evaluated as 'an enduring personality trait'. In their review of the role of nature versus nurture, McCrae., Costa, Ostendorf, Angleitner, Hrebícková et al. (2000, p. 173) define personality trait as an 'acquired pattern of thought and behaviour'. While this debate is outside the scope of this study, Type A and Type B behaviour will be viewed as a cluster of personality traits and the corresponding behavioural tendencies.

Historically, research has focused on the role of Type A behaviour and coronary heart disease (CHD). While there have been inconsistent findings in the link between the two, recent research by Gallacher, Sweetnam, Yarnell, Elwood, and Stansfeld (2003) has found support for the trigger hypothesis, in that Type A behaviour 'increases exposure to potential triggers' (p. 339). Other research has explored individual Type A behavioural traits. For example, Krantz and McCeney (2002) noted that the hostility component in Type A behaviour to be a risk factor for CHD, while Boyle, Williams, Mark, Brummett, Siegler et al. (2004) have identified hostility as a factor associated with poorer health outcomes for patients with CHD. As this debate continues, further investigation of Type A behaviour is warranted, not only in terms of the link with CHD, but also the possible links with other personality traits.

In the present research, a global measure of the Type A behaviour and a measure of materialism developed by Richins and Dawson (1992) were administered to a 193 participants chosen randomly from a regional telephone directory. Richins and Dawson (1992) propose that once the moral and societal consequences of materialism are removed, three general premises remain. 'Acquisition centrality' implies that the acquisition and possession of material goods and services forms the central goal in an individual's lifestyle. 'Acquisition as the pursuit of happiness' suggests that the reason that the possession and acquisition of goods and services are central to the person is that they are believed to provide a substantial contribution to life satisfaction. If persons within a market-driven society are differentiated by what they possess, rather than who they are, then it is most likely that they consider both their own and other's value (or worth) as something that is externally and competitively determined by both the number and quality of possessions accumulated. This is what is meant by the third theme, 'possession-defined success'. Support for the relationship between this specific subscale and competitive attitudes and the anger that might be associated with such goal-directed behaviours is provided by Saunders (2007) and Saunders (2006).

Considering the results of the studies cited above, it would appear that both Materialism, and particularly, the possession-defined Success theme described by 
Richins and Dawson (1992) has characteristics in common with specific Type A behaviours such as competitiveness and aggressiveness. Furthermore, Peterson and Wilson's (2004) editorial of work stress in America proposes that there are six primary cultural roots, with both materialism and Type A behaviour falling under the same cultural value of work and wealth. While American culture was the focus of Peterson and Wilson's theoretical investigation, Australia, like America, is viewed as an individualistic culture with Australian materialists valuing a comfortable life (Saunders, in press). As such, while there are cultural differences between Australia and America, the theoretical assumption linking materialism and Type A behaviour of Peterson and Wilson's work may also be applicable to an Australian sample. Therefore, it is hypothesised that both Materialism, and more so the Success subscale, will be positively correlated with Type A behaviour.

\section{Method \\ Participants}

The respondents in this study were 193 persons (112 males and 81 females, mean age 48.8 yrs, range $18-91$ years).

\section{Instruments}

Richins and Dawson (1992) Materialism scale: comprises 18 items, using a 5-point Likert scale response format (anchored by strongly disagree and strongly agree), and divided between the three themes introduced above. In this study, a coefficient alpha of .86 was found for the entire scale, and .78, .71 and .81 for centrality, happiness, and success subscales respectively. Test-retest reliability is quoted as .87 for the combined scale, and $\mathrm{r}=.82, .86$, and .82 respectively for the subscales. Saunders (2000) reported that social desirability effects did not adversely influence the scale.

Type A and Type B behaviour scale (Bortner, 1969): comprises seven items, measured on an 8-point Likert scale response format anchored by the following opposing statements: (1) 'Am casual about appointments' versus 'Am never late'; (2) 'Am not competitive' versus 'Am very competitive'; (3) 'Never feel rushed, even under pressure' versus 'Always feel rushed'; (4) 'Take things one at a time' versus 'Try to do many things at once; think about what I'm going to do next'; (5) 'Do things slowly' versus 'Do things fast'; (6) 'Express feelings' versus " $S i t$ " on feelings'; (7) 'Have many interests' versus 'Have few interests outside work'. Low scores denote Type B behaviour, with higher scores describing Type A behaviour. In this study, a coefficient alpha of .50 was found for entire scale. Although less than desired, this may in part be due to the small number of items. Factors influencing the choice of this short global measure were that aside from the finding that there was no evidence of previous research investigating links between materialism and
Type A and B behaviour in general, participants also completed other questionnaires that were not related to this study, hence the need for brevity.

\section{Procedure}

A 10-page survey was distributed through the post to a sample of 500 residents randomly selected from a regional telephone directory from Newcastle, New South Wales (which is one of two commonly preferred test markets for consumer goods in Australia). The random selection process involved two steps. First, a computer was used to generate a random number, after which the researchers selected every $n$-th name in the phonebook (where $n=$ the random number selected by the computer). Potential respondents were told, 'The questionnaires in this survey seek to evaluate individuals' lifestyles and associated attitudes'. Respondents were encouraged to return the questionnaire within three weeks, and those unwilling or unable to participate were urged to pass the questionnaire along to another household member who was at least 18 years old. Two hundred were returned (40\%), of which 193 were useable.

\section{Results}

The results were calculated using Minitab V13, and correlations between Materialism and scores on Type A, Age and Gender can be seen in Table 1. Note, though, that in accordance with the conservative criteria suggested by Williams and Page (1989) for rejecting null hypotheses, correlations of less than $r=.20$ will not be evaluated as significant regardless of the possible effect of sample size.

In Table 1, scores on Type A behaviour are not statistically significantly correlated with age or gender, but are significantly correlated with Materialism total scores and also the possession-defined Success subscale of Materialism. Hence, as scores on this subscale increase, the likelihood of participants rating as a Type A behaviour also increases significantly. The Success subscale of the Materialism index is also not statistically significantly correlated with age or gender.

In order to better understand the relationship between Materialism and Type A behaviour, in Table 2 are correlations between Materialism and its subscales and the individual items in the Type A behaviour index. In Table 2, there is only one statistically significant correlation, between the Success subscale and Type A item 2: Am not competitive versus Am very competitive.

\section{Discussion}

The hypothesis that scores on Materialism would be positively correlated with Type A behaviour was supported. Furthermore, the hypotheses that the Success subscale would be positively correlated with Type A behaviour - and more so than scores on the entire materialism instrument - were also supported. 
Table 1

Correlations between Type A Behaviour, Age, Gender*, and Materialism (Success, Centrality, and Happiness subscales)

\begin{tabular}{|c|c|c|c|c|c|c|}
\hline & Gender & Age & Materialism & Type A & Success & Central \\
\hline \multirow[t]{2}{*}{$\overline{\text { Age }}$} & -0.29 & & & & & \\
\hline & 0.000 & & & & & \\
\hline \multirow[t]{2}{*}{ Materialism } & -0.04 & -0.20 & & & & \\
\hline & 0.604 & 0.006 & & & & \\
\hline \multirow[t]{2}{*}{ Type A } & -0.18 & 0.02 & 0.20 & & & \\
\hline & 0.012 & 0.804 & 0.008 & & & \\
\hline \multirow[t]{2}{*}{ Success } & -0.19 & 0.03 & 0.78 & 0.24 & & \\
\hline & 0.056 & 0.667 & 0.000 & 0.001 & & \\
\hline \multirow[t]{2}{*}{ Central } & 0.08 & -0.34 & 0.77 & 0.08 & 0.38 & \\
\hline & 0.259 & 0.000 & 0.000 & 0.257 & 0.000 & \\
\hline \multirow[t]{2}{*}{ Happiness } & -0.03 & -0.16 & 0.79 & 0.13 & 0.47 & 0.40 \\
\hline & 0.690 & 0.032 & 0.000 & 0.075 & 0.000 & 0.000 \\
\hline
\end{tabular}

Note: Cell Contents: Pearson correlation; P-Value

* point biserial correlations, where male $={ }^{\prime} 1$ ', female $={ }^{\prime} 2$ '

However (and in view of the stringent criteria adopted in the present study for rejecting null hypotheses), further analyses revealed that the Success subscale was only statistically significantly correlated with the second individual Type A item, which assessed respondents' competitiveness.

Given previous research has suggested a link between the Success scale and competitive behaviours (Saunders, 2007), considered in isolation the above finding is not surprising. However, the absence of any statistically significant correlations between other Type A behaviour items and scores on Materialism and its associated subscales is. For example, after even a brief review of commentary offered by critics of the modern consumeroriented lifestyle, one might assume that people with obvious materialistic inclinations might describe their lifestyles as being hectic, time-poor, and pressure-inducing (i.e., as per items 3,4 , and 5 on the Type A behaviour index employed in this study). An example of this would be Fromm's (1955) 'marketing character', in which the self is experienced as a commodity whose value and meaning is externally determined and for whom, 'the concept of happiness is tied to consumption' (Fromm, 1970, as cited in Funk, 1993, p. 73) and 'things, experience, time and life itself are seen as possessions to be acquired and retained' (Belk, 1988, p. 146). The current results might cast such assumptions into doubt. Still, it might also be considered that behaviours are not always concordant with what we want or value.

With due deference to Fromm, though, the Materialism instrument designed by Richins and Dawson (1992) aims to measure individuals' affinity with conspicuous purchase items only, as opposed to the marketing character which is based on the notion of 'homo consumens' - that is, a consumer of all experiences - and would be expected to encompass a broader range of values and behaviours than Richins and Dawson's contemporary Materialism instrument. Hence, future research will reevaluate the present results using an instrument already developed and validated (i.e., the Saunders Consumer Orientation Index, Saunders \& Munro, 2000) to assess Fromm's (1955) marketing character.

\section{Table 2}

Correlations between Materialism, and Success, Centrality, and Happiness Subscales and lindividual Items from the Type A Behaviour Index

\begin{tabular}{llllllll}
\hline & Type a1 & Type a2 & Type a3 & Type a4 & Type a5 & Type a6 & Type a7 \\
\hline Matt & 0.06 & 0.17 & 0.14 & 0.11 & 0.06 & 0.06 & 0.06 \\
& 0.418 & 0.017 & 0.050 & 0.132 & 0.394 & 0.421 & 0.405 \\
Success & 0.16 & 0.29 & 0.09 & 0.05 & 0.04 & 0.13 & 0.14 \\
& 0.028 & 0.000 & 0.218 & 0.527 & 0.542 & 0.069 & 0.054 \\
Central & -0.08 & 0.05 & 0.16 & 0.14 & 0.06 & -0.08 & -0.08 \\
& 0.302 & 0.531 & 0.031 & 0.047 & 0.424 & 0.292 & 0.253 \\
Happiness & 0.05 & 0.06 & 0.10 & 0.08 & 0.04 & 0.07 & 0.09 \\
& 0.470 & 0.420 & 0.177 & 0.249 & 0.553 & 0.324 & 0.199 \\
\hline
\end{tabular}

Note: Cell Contents: Pearson correlation; P-Value 
Another explanation for the present results may be that a global measure of Type A behaviour was used in this study, while some researchers argue that individual components of Type A behaviour should be assessed. For example, Spence, Helmreich, and Pred (1987) proposed that Type A behaviour comprises of two independent components: achievement striving (AS) and impatience-irritability (II). The former reflects the hardworking and active traits of Type A behaviour while the latter not only incorporates impatience and irritability, but also the anger and time pressure traits (Spence et al., 1987). Day and Jreige's (2002) research on job stressors and psychosocial outcomes supported that the AS and II components are independent. Research by Bruck and Allen (2003) found that only the II component correlated with work-family conflict, thus suggesting that the assessment of individual components is more appropriate than a global measure of Type A behaviour. However, other components of Type A behaviour have also been outlined. Edwards and Baglioni (1991) proposed that the two components are time pressure and hard-driving competitiveness. Regardless of which particular components are proposed, one can argue that traits such as achievement striving (including competition), impatience, and time pressure conceptually overlap with traits associated with materialism and modern consumer behaviours. Further support for investigating individual components underlying Type A behaviour is argued for by the fact that the present results, while statistically significant, show only lowrange correlation between materialism and a global measure of type A behaviour. Indeed, the highest correlation (but still only $r=0.29$ ) was found between the materialism Success subscale and an individual Type A item measuring competitiveness.

Finally, it must be stressed that directions of causality cannot be inferred from the present results: while it may indeed be that materialistic pursuits provide a culturally sanctioned outlet for competitive behaviours that derive from existing Type A behaviour, it may also be the case that contemporary consumer society encourages such behaviours where they might not otherwise court attention. In light of the present results and discussion, it is suggested that future research not only investigate the relationships between different definitions of modern materialistic values and attitudes and Type A behaviour, but also consider individual components of Type A behaviour rather than global measures.

\section{References}

Allen, M.W., \& Wilson, M. (2005). Materialism and food security. Appetite, 45, 314-323.

Belk, R. (1988). Possessions and the extended self. Journal of Consumer Research, 15, 139-168.
Bortner, R. (1969). A short rating scale as a potential measure of Pattern A behavior. Journal of Chronic Diseases, 22, 87-91.

Boyle, S.H., Williams, R.B., Mark, D.B., Brummett, B.H., Siegler, I.C., Helms, M.J., et al. (2004). Hostility as a predictor of survival in patients with coronary artery disease. Psychosomatic Medicine, 66(5), 629-632.

Bruck, C. S., \& Allen, T. D. (2003). The relationship between big five personality traits, negative affectivity, Type A behavior, and work-family conflict. Journal of Vocational Behavior, 63, 457-472.

Chang, L.C., \& Arkin, R.M. (2002). Materialism as an attempt to cope with uncertainty. Psychology \& Marketing, 19(5), 389-406.

Chatterjee, A., \& Hunt, J.M. (1996). Self-monitoring as a personality correlate of materialism: An investigation of related cognitive orientation. Psychological Reports, 79(2), 523-528.

Claxton A., \& Murray, J.B. (1994). Object-subject interchangeability: A symbolic interactionist model of materialism. Advances in Consumer Research, 21, 422-426.

Day, A.L., \& Jreige, S. (2002). Examining Type A behavior pattern to explain the relationship between job stressors and psychosocial outcomes. Journal of Occupational Health Psychology, 7(2), 109-120.

Dollard, J., Doob, L., Miller, N., Mowrer, O., \& Sears, R. (1939). Frustration and aggression. New Haven, CT: Yale University Press.

Edwards, J.R., \& Baglioni, A.J., Jr. (1991). Relationship between Type A behavior pattern and mental and physical symptoms: A comparison of global and component measures. Journal of Applied Psychology, 76(2), 276-290.

Fromm, E. (1955). The sane society. New York: Holt, Rinehart, \& Winston.

Funk, R. (Ed.). (1993). The essential Fromm. London: Constable.

Gallacher, J.E.J., Sweetnam, P.M., Yarnell, J.W.G., Elwood, P.C., \& Stansfeld, S.A. (2003). Is Type A behavior really a trigger for coronary heart disease events? Psychosomatic Medicine, 65, 339-346.

Holt, D.B. (1995). How consumers consume: A typology of consumption practices. Journal of Consumer Research, 22, $1-16$.

Inglehart, R. (1977). Silent revolution: Changing values and political styles among Western publics. Princeton, NJ: Princeton University Press.

Inglehart, R. (1997). Modernization and post modernization: Cultural, economic, and political change in 43 societies. Princeton, NJ: Princeton University Press.

Kasser, T., \& Grow Kasser, V. (2001). The dreams of people high and low in materialism. Journal of Economic Psychology, 22(6), 693-719.

Krantz, D.S., \& McCeney, M.K. (2002). Effects of psychological and social factors on organic disease: A critical assessment of research on coronary heart disease. Annual Review of Psychology, 53(1), 341-369.

McCrae, R.R., Costa, P.T., Jr., Ostendorf, F., Angleitner, A., Hrebícková, M. Avia, M.D., et al. (2000). Nature over 
nurture: Temperament, personality, and life span development. Journal of Personality and Social Psychology, 78(1), 173-186.

Peterson, M., \& Wilson, J. F. (2004). Work stress in America. International Journal of Stress Management, 11(2), 91-113.

Richins, M. (1994). Special possessions and the expression of material values. Journal of Consumer Research, 21, 522-533.

Richins, M., \& Dawson, S. (1992). A consumer values orientation for materialism and its measurement: Scale development and validation. Journal of Consumer Research, 19, 303-316.

Saunders, S. (2000). An examination of Fromm's (1955) marketing character and materialistic attitudes and their relationship to psychological health and contemporary issues. Unpublished doctoral thesis, University of Newcastle, Australia.

Saunders, S. (2001). Fromm's marketing character and Rokeach values. Social Behavior and Personality, 29(2), 191-196.

Saunders, S. (2006). An examination of Fromm's (1955) marketing character and materialistic attitudes and their relationship to psychological health. Hawaii International Conference on Social Sciences, Hawaii.

Saunders, S. (2007). An exploratory look at materialism and individualism and collectivism. Manuscript submitted for publication.

Saunders, S. (in press). A snapshot of five materialism studies in Australia. Journal of Pacific Rim Psychology.

Saunders, S., \& Allen, M. (2000). Materialism and life satisfaction in Australia: Is more better? South Pacific Journal of Psychology, 12(1), 48-51.
Saunders, S., \& Munro, D. (2000). The construction and validation of a consumer orientation questionnaire (SCOI) designed to measure Fromm's (1955) 'Marketing Character' in Australia. Social Behavior and Personality, 28(3), 219-240.

Saunders, S., \& Munro, D. (2001). A psychological profile of materialism in Australia [Abstract]. Proceedings of the 100th Anniversary of the British Psychological Society/7th European Congress of Psychology, London.

Saunders, S., Munro, D., \& Bore, M. (1998). Maslow's hierarchy of needs and its relationship with psychological health and materialism. South Pacific Journal of Psychology, 10(2), $15-25$.

Schroeder, J.E., \& Dugal, S.S. (1995). Psychological correlates of the materialism construct. Journal of Social Behaviour and Personality, 10(1), 243-253.

Singelis, T.M., Triandis, H.C., Bhawuk, D.P.S., \& Gelfand, M.J. (1995). Horizontal and vertical dimensions of individualism and collectivism: A theoretical and measurement refinement. Cross-Cultural Research, 29, 240-275.

Spence, J.T., Helmreich, R.L., \& Pred, R.S. (1987). Impatience versus achievement strivings in the Type A pattern: Differential effects on students' health and academic achievement. Journal of Applied Psychology, 72(4), 522-528.

Thoresen, C.E., \& Powell, L.H. (1992). Type A behavior pattern: New perspectives on theory, assessment, and intervention. Journal of Consulting and Clinical Psychology, 60(4), 595-604.

Vecchio, R.P., Hearn, G., \& Southey, G., (1996). Organisational behaviour (2nd ed.). Sydney, Australia: Harcourt Brace.

Williams, D., \& Page, M. (1989). A multi-dimensional measure of Maslow's hierarchy of needs. Journal of Research in Personality, 23, 192-213. 